\title{
A construção da autonomia na sala de aula de língua estrangeira
}

\author{
Célia Angélica Limani Boisson Moraes \\ Centro de Idiomas Ann Arbor - RJ \\ Paula Silveira Gardel \\ Centro de Idiomas Ann Arbor - RJ
}

\section{Resumo}

Nesta pesquisa buscamos refletir sobre o papel da autonomia na aprendizagem de inglês como língua estrangeira. O nosso objetivo foi promover a autonomia de alunos em uma sala de aula através da conscientização e construção de estratégias. Para tal, conduzimos um trabalho em duas turmas de inglês básico constituídas de alunos entre nove e onze anos. Em um primeiro momento, fizemos uma pesquisa exploratória envolvendo toda a turma, com a finalidade de entender como os alunos vivenciavam a autonomia fora e dentro da sala de aula. A partir desse entendimento, propusemos a construção de um pôster para promovermos maior autonomia. Para nossa análise final e avaliação de nossos objetivos, utilizamos as gravações, anotações e questionários feitos durante o período da pesquisa.

Palavras-chave: autonomia, estratégias, sala de aula, construção de conhecimento.

\begin{abstract}
This research aims at investigating the role of autonomy in learning English as a foreign language. Our purpose was to encourage student autonomy in the classroom by promoting their awareness and by building new strategies. For such, the investigation was carried out in two basic level classes made up of nine to eleven year old students. At first, we carried out an exploratory research involving all the class with the objective of understanding how our students experienced autonomy both in and out of the classroom. Having reached this understanding, we suggested making a poster to promote further autonomy. For the final analysis and evaluation of our purposes we used the recordings, notes and questionnaires obtained during our research.
\end{abstract}

Key words: autonomy, strategies, classroom, knowledge construction. 


\title{
INTRODUÇÃO
}

"Ensinar não é transferir conhecimento, mas criar possibilidades para a sua própria produção ou a sua construção.”

(Paulo Freire)

\begin{abstract}
Dentro da visão sociohistórica, a interação e a construção coletiva de conhecimento são fundamentais no processo educacional. De acordo com essa perspectiva, a aprendizagem deixa de ser simplesmente a reprodução de um conhecimento já existente para tornar-se um processo de desenvolvimento cognitivo em que o individual e o coletivo se complementam e se manifestam na interação. Esse processo pressupõe uma organização discursiva em sala de aula mais equilibrada e um aluno mais autônomo e consciente. O papel do professor passa a ser o de facilitador no processo da aprendizagem e no desenvolvimento da autonomia de seus alunos. Ou seja, a aprendizagem ocorre em um processo interacional em que alunos e professor trabalham juntos na construção de um novo conhecimento. O aprendiz, nessa visão de ensino, é co-construtor e gerente de sua aprendizagem, e não simplesmente um receptor de conhecimento. Essa habilidade de co-construir e gerenciar sua própria aprendizagem é o que conhecemos como autonomia, e ela pode ser aplicada em quaisquer áreas de ensino. No caso de ensino de línguas, Nunan (2000:3) ressalta que “a aprendizagem de uma segunda língua ocorrerá com mais eficácia se os aprendizes puderem desenvolver e exercer a sua autonomia." "Tal afirmação coloca a autonomia como uma das molas propulsoras para uma aprendizagem eficaz e sustentável.
\end{abstract}

A sala de aula tradicional nem sempre deu espaço para que o aluno buscasse seus próprios caminhos no seu desenvolvimento cognitivo. Por outro lado, a perspectiva sociohistórica com sua ênfase na interação dá voz ao aluno permitindo que ele traga para a sala de aula o seu entendimento das questões apresentadas em sala, e destaca a intervenção do professor no desenvolvimento cognitivo do aluno.

Nos últimos anos, o papel da autonomia na aprendizagem de língua estrangeira ganhou destaque em várias pesquisas no Brasil e no mundo (Leffa, 2002; Nunan, 2000; Oliveira e Paiva, 2005; Nicolaides, 2005). Muitas dessas pesquisas indicam que o aluno autônomo é mais bem sucedido dentro e fora da sala (Leffa, 2002; Nunan, 2000;

\footnotetext{
1 “...second language learning will proceed most effectively if learners are allowed to develop and exercise their autonomy.”
} 
Nicolaides, 2005). Neste trabalho buscamos investigar o papel da autonomia na aprendizagem de língua estrangeira e promover a conscientização dos nossos alunos sobre a importância da autonomia. Acreditamos que essa investigação possa não só esclarecer questões sobre a aprendizagem, como também indicar caminhos para ensinar a autonomia na sala de aula.

A fim de compreender o papel da autonomia na aprendizagem de segunda língua, faremos uma breve discussão do conceito de autonomia e sua relação com o ensino-aprendizagem. Também discutiremos as estratégias que envolvem a aplicação desse conceito no contexto da sala de aula.

\section{CONSIDERAÇÕES TEÓRICAS}

As abordagens interacionais de ensino diferem da maior parte das abordagens tradicionais em uma noção que é central: o conhecimento é construído socialmente na interação com o outro. Na escola de idiomas onde o presente trabalho foi conduzido seguimos uma abordagem primordialmente interacional. De acordo com essa perspectiva, o desenvolvimento da autonomia deve ser incentivado, pois é através da participação ativa, autônoma e consciente que podemos levar nossos a alunos a uma aprendizagem sustentável e eficaz.

Pesquisas na área de ensino demonstram a relevância da autonomia no processo de aprendizagem, havendo um consenso entre alguns autores de que a autonomia deve ser desenvolvida e ensinada (Leffa, 2002; Moita Lopes, 1997). Segundo Leffa (2002:15) “a aprendizagem que realmente interessa, aquela que não é apenas reprodução do que já existe, mas criação de algo novo, de progresso e avanço, só é possível com autonomia.” Ou seja, como educadores devemos desenvolver em nossos alunos um conhecimento que vai além do conhecimento ritualístico e mecânico; temos que incentivar a participação ativa e consciente, pois só esse tipo de competência libertará o aluno da dependência do professor (Moita Lopes, 1997). Antes porém de desenvolvermos uma discussão sobre a autonomia no ensino-aprendizagem, discutiremos alguns conceitos de autonomia e apresentaremos o conceito que nos propusemos a aplicar em nossa investigação. 


\section{O QUE É AUTONOMIA?}

Para o senso comum, autonomia significa liberdade e independência. Quando pensamos em um sujeito autônomo a imagem que nos vem na mente é a de um sujeito capaz de reger suas escolhas de forma reflexiva. Ou seja, um indivíduo consciente e protagonista de sua própria história e evolução.

Muitos autores ligados às questões de ensino-aprendizagem apresentaram conceitos de autonomia que merecem ser revistos e apresentados aqui, posto que adicionam características importantes a esta capacidade. Para Holec (1981 apud Paiva, 2005) autonomia é a habilidade de responsabilizar-se pela própria aprendizagem. Nessa concepção de autonomia a ênfase está na independência do indivíduo, porém não abrange o aspecto reflexivo do comportamento autônomo. Já para Little (1991 apud Paiva, 2006:82) autonomia é a “capacidade de planejar, monitorar e avaliar as atividades de aprendizagem, e, necessariamente, abrange tanto o conteúdo quanto o processo de aprendizagem.” Nessa definição o aspecto da reflexão na aprendizagem é ressaltado. Além disso, o autor acrescenta que a autonomia na aprendizagem não deve se limitar a habilidades referentes ao conteúdo, ou melhor, ao domínio de uma tarefa específica, mas deve também considerar aspectos metacognitivos que dizem respeito ao processo de aprendizagem, ou seja, o entendimento das estratégias que envolvem esse processo. O conceito de autonomia apresentado por Little (1991) se alinha ao pensamento de Moita Lopes (1997) que afirma que os alunos devem entender o propósito geral das atividades e refletir sobre seu próprio conhecimento a fim de poder utilizar esse conhecimento em outros contextos.

No entanto, alguns autores acreditam que autonomia não é compatível com o ensino formal e com a escola (Candy, 1989; Crabbe, 1993), uma vez que essa habilidade contraria o modelo tradicional de ensino. Para Candy (1989 apud Paiva, 2005:83) a "autonomia é uma capacidade inata do indivíduo que pode ser suprimida ou distorcida pela educação formal.” Por outro lado, outros autores defendem a idéia de que a autonomia é uma habilidade que pode ser ensinada e incentivada nas escolas (Leffa, 2002; Freire, 1977; Moita Lopes, 1997). De acordo com Freire (1996) autonomia está ligada à liberdade e à capacidade do aprendiz em construir e reconstruir o saber ensinado. Também Leffa (2002) ao discutir a autonomia e o ensino, afirma que é possível ensinar o aluno a ser autônomo, e que cabe a escola promover condições para que essa habilidade seja desenvolvida. 
Para este trabalho, escolhemos alguns aspectos da autonomia apresentados por Paiva (2005) para elaborar o conceito de autonomia que nos propusemos a seguir nesta investigação. São quatro aspectos:

1. Autonomia requer consciência do processo de aprendizagem;

2. Autonomia, inevitavelmente, envolve uma mudança nas relações de poder;

3. O professor pode ajudar o aprendiz a ser autônomo tanto na sala de aula quanto fora dela;

4. Autonomia está intimamente relacionada às estratégias metacognitivas; planejar/tomar decisões, monitorar, e avaliar.

Temos constatado em nossa prática diária em sala de aula que dar a oportunidade ao aprendiz de fazer escolhas entre diferentes alternativas é fundamental no processo que envolve formação de alunos autônomos. Acreditamos que a autonomia tem um papel importante na aprendizagem. Discutiremos a seguir algumas teorias de ensino-aprendizagem que colocam a autonomia como um dos fundamentos do "bom aprendizado.”

\section{AUTONOMIA E APRENDIZAGEM DE LÍNGUAS}

A questão da autonomia no ensino-aprendizagem de línguas é relativamente nova. Durante muitos anos, os métodos de ensino de línguas se caracterizavam por terem uma estrutura de participação centrada no professor, em um padrão discursivo conhecido como IRA $^{2}$ (Iniciação-Resposta-Avaliação). Esse tipo de organização discursiva é assimétrica, controlada e centrada no professor, e, portanto não promove nenhum tipo de autonomia para o aluno. Os métodos direto e áudiolingual, que por décadas dominaram as salas de aula de línguas, adotavam essa estrutura discursiva. Porém, com o advento da abordagem comunicativa, houve uma guinada no aspecto interacional na sala de aula. A competência comunicativa passa a ser o objetivo principal do ensino de línguas, e o caminho para alcançar tal competência está na interação e na autonomia.

Uma outra contribuição importante para o ensino-aprendizagem de línguas é a da teoria sociocultural. Essa teoria, desenvolvida por Vygotsky (1896-1934), preconiza

\footnotetext{
${ }^{2}$ IRF - iniciation-response-feedback
} 
que o conhecimento é construído socialmente na interação e que a intervenção pedagógica, aplicada no momento certo, não só acelera a aprendizagem como produz autonomia. Ao discutir as idéias de Vygotsky na aprendizagem de línguas, Leffa (2002) diz que a teoria Vygotskiana evita o automatismo no ensino, pois abre espaço para um tipo de intervenção pedagógica que envolve o controle consciente do aluno na sua própria aprendizagem. Moita Lopes (1997:97) explica essa intervenção da seguinte forma:

\footnotetext{
o professor tem a função central de construir andaimes para o aluno aprender, de modo que o aprendiz converta o conhecimento externo em seu próprio, desenvolvendo controle consciente sobre o mesmo. É este controle consciente por parte do aluno que caracteriza a passagem da competência ou handover.
}

Ou seja, como professores, devemos guiar nossos alunos para atingir um novo conhecimento através de uma ação conjunta que implica participação ativa e conscientização. Na perspectiva sociocultural podemos sempre expandir os limites do conhecimento através da assistência cognitiva guiada, que pode ser promovida não só pelo professor como por outros tipos de mediação. O que é importante destacar sobre a proposta sociohistórica é que “ainda que o desempenho do aluno tenha que ser assistido durante um certo período, há pelo menos a previsão de que no futuro o aluno será capaz de executar a tarefa por conta própria; a autonomia é um estágio a que se chega” (Leffa, 2002:4).

Neste trabalho procuramos nos basear nas premissas das abordagens comunicativa e sociohistórica para explicar e justificar a importância da autonomia no ensino-aprendizagem de línguas. A seguir discutiremos formas de desenvolver essa autonomia em sala de aula.

\section{DESENVOLVIMENTO DA AUTONOMIA NA SALA DE AULA}

Ao discutir o desenvolvimento da autonomia na educação, Leffa (2002) afirma que é possível ensinar alguém a ser autônomo criando oportunidades em sala de aula. Acreditamos que como educadores devemos nos mobilizar no sentido de dar ferramentas aos nossos alunos para que possam se tornar autônomos, ou seja, é fundamental que o professor utilize estratégias e promova meios facilitadores de aprendizagem. Na abordagem sociohistórica, o professor deve ser o mediador no desenvolvimento cognitivo do aluno. Segundo Larsen-Freeman (2002), não é suficiente apenas reconhecer as contribuições feitas pelos alunos, é necessário também que o 
professor procure maximizar o potencial de seus alunos com a utilização de estratégias e conscientizá-los envolvendo-os em relação à importância do trabalho autônomo.

Sobre o ensino de línguas, Wenden (1985, apud Larsen-Freeman, 2002) observou que o tempo dedicado ao ensino e prática de estratégias em sala de aula é tão valioso quanto aquele dedicado ao ensino e prática da língua. Seguindo essa mesma linha de pensamento, Freitas (1998:70) concorda que “o ensino sistematizado e formalizado do uso de estratégias de aprendizagem na aquisição de uma nova língua não é só possível como necessário porque, além de melhorar o desempenho linguístico do aluno, encoraja a sua autonomia.”

Dentro dessa perspectiva, o uso de estratégias parece ser de grande valia, posto que instrumentaliza o aluno a desenvolver-se sozinho e conscientizar-se do processo de aprendizagem. Ao discutir a importância do uso de estratégias no ensino-aprendizagem de línguas, Larsen-Freeman (2002:164) conclui que “um benefício adicional do ensino e prática de estratégias é que este treinamento pode ajudar o aluno a continuar a sua aprendizagem depois de haver concluído o estudo formal na língua alvo. ${ }^{3 \text { ” }}$

Nunan (2000), em seu texto sobre autonomia, lista quatro estratégias para fomentar a autonomia em sala de aula. São elas:

1) Integrar o conteúdo da linguagem ao processo de aprendizado (deixando claros os objetivos, promovendo oportunidades para reflexão, autoavaliação, dando escolha, etc.)

2) Incentivar aulas reflexivas.

3) Redigir contratos de aprendizagem.

4) Montar diários com o aluno.

As estratégias propostas por Nunan (2000) visam desenvolver algumas características que consideramos importantes na autonomia: a responsabilidade, a conscientização, e a reflexão. Em nosso trabalho também procuramos desenvolver esses aspectos a fim de impulsionar os alunos a assumir uma posição mais independente dentro de sala de aula. Demonstraremos agora o percurso de nossa pesquisa sobre construção da autonomia através do uso de estratégias.

\footnotetext{
${ }^{3}$ An added benefit of learning strategy training is that it can help learners to continue to learn after they have completed their formal study of the target language.
} 


\section{PROCEDIMENTOS}

O presente trabalho foi realizado em uma escola de idiomas, com duas turmas de inglês de nível básico e duas professoras diferentes. Uma das turmas era constituída de oito alunos, com idades entre nove a dez anos, sendo três meninas e cinco meninos. A outra com dez alunos, com idades entre nove a onze anos, sendo três meninas e sete meninos. O trabalho teve a duração de dois meses. Como já mencionado, com base nos pressupostos teóricos, o foco da pesquisa foi analisar a importância da autonomia na aprendizagem de uma segunda língua. Nosso objetivo maior foi refletir, junto aos alunos, sobre o tema autonomia dentro e fora de sala de aula e criar estratégias para fomentar a autonomia em nossas aulas.

Em um primeiro momento, gravamos em vídeo uma atividade de language analysis (Anexo1) em sala de aula. Essa atividade consiste em um exercício de correção de erros referentes ao uso da língua, cometidos em sala de aula e previamente registrados pela professora. O objetivo era verificar o grau de autonomia dos alunos em uma atividade que é recorrente em nossas aulas. Em seguida, com o objetivo de trabalhar o conceito de autonomia junto aos alunos, propusemos uma discussão a partir das seguintes perguntas:

1. O que é autonomia para vocês?

2. O que é agir com autonomia?

3. Você pode contar alguma história em que agiu com autonomia?

4. Que benefícios isso lhe trouxe?

A partir dos depoimentos dos alunos, discutimos os benefícios da autonomia na vida deles. Como passo seguinte, transferimos essas questões para o contexto da sala de aula perguntando como poderíamos tornar a turma mais responsável e menos dependente da professora.

Na aula seguinte, o vídeo gravado foi mostrado para a turma e analisado por todos. A partir dessa análise, várias sugestões de atitudes mais autônomas foram feitas. Em seguida, pedimos que os alunos refletissem e selecionassem as atitudes que consideravam mais importantes para serem colocadas em prática nas aulas. Propusemos então a elaboração de um pôster contendo um conjunto de estratégias para fomentar a autonomia (Anexo 2). Uma vez pronto, o pôster foi pendurado no mural da sala e os 
alunos passaram a se reportar a ele durante as atividades. Além disso, ao final de cada aula, os alunos faziam uma avaliação do desempenho do grupo em relação às propostas contidas no pôster.

Após o primeiro mês, avaliamos com os alunos a eficiência das estratégias listadas no pôster. Após essa avaliação, algumas estratégias foram retiradas e novas foram acrescentadas.

No final do semestre, pedimos que os alunos respondessem a um questionário (Anexo 3) para que pudéssemos verificar se o nosso objetivo havia sido alcançado, a saber: promover a autonomia dos alunos através da conscientização e construção de estratégias.

\section{ANÁLISE}

Ao iniciarmos a nossa pesquisa decidimos que era importante avaliar o grau de autonomia das nossas turmas antes de tomar qualquer atitude de intervenção. Essa avaliação foi feita em duas etapas. Em um primeiro momento, fizemos uma observação livre de várias atividades conduzidas em sala de aula. Em um segundo momento, para uma observação mais pontual e detalhada, escolhemos uma atividade de language analysis (Anexo 1) para a avaliação. A decisão por essa atividade se deu porque o exercício de language analysis permite que os alunos interajam sem a interferência da professora, ou seja, com algum grau de autonomia. Ao analisarmos os dados contidos na observação livre e na atividade de language analysis, verificamos alguns pontos comuns nas duas turmas:

1. Os alunos são capazes de trabalhar sozinhos em algumas atividades;

2. Os alunos são capazes de corrigir uns aos outros com eficiência;

3. Os alunos solicitam primeiro a professora quando têm dúvidas;

4. Os alunos utilizam poucos recursos para checar informação, na maior parte das vezes esse recurso é o dicionário;

5. Alguns alunos participam mais que outros;

6. Os alunos não participam da elaboração do plano da aula colocado no quadro;

7. A professora é a única responsável pelo cumprimento do plano da aula;

8. Os alunos não refletem sobre suas atitudes durante as aulas; 
Esses pontos revelaram que embora as duas turmas trabalhassem com algum grau de autonomia durante atividades específicas, como o language analysis, em outros momentos os alunos tinham uma atitude passiva e dependente da professora. Ou seja, havia em ambas as turmas capacidade para uma aula mais autônoma, mas este potencial não estava sendo maximizado.

Em nossa observação, destacamos dois pontos que consideramos exemplos de comportamento autônomo: capacidade para trabalhar sem a intervenção da professora e capacidade de auto-correção e correção entre colegas ${ }^{4}$. As atividades onde essas capacidades foram observadas foram: a conversa sobre o final de semana, a correção de dever de casa, o exercício language analysis e as apresentações orais. Essas atividades são recorrentes em nossas aulas e se caracterizam por serem conduzidas com o mínimo de interferência da professora. Observamos, no entanto, que quando surgia algum tipo de impasse, os alunos buscavam de imediato o auxílio da professora, desconsiderando muitas vezes a contribuição do colega ou mesmo do livro e do caderno para solucionar as dúvidas. No que tange a interação, verificamos que alguns alunos assumiam o papel do professor, fazendo a maior parte das correções, enquanto outros ficavam esperando ser chamados a participar. Observamos também que ao colocar o plano de aula no quadro sem qualquer tipo de negociação com a turma, a professora acabava assumindo toda a responsabilidade pelo cumprimento das tarefas propostas, pois para os alunos o plano era de autoria dela, e não da turma. Dessa forma, o compromisso que os alunos assumiam com o plano da aula não era consciente e reflexivo, mas sim resultado da autoridade e vontade da professora.

Tendo como base essa avaliação, partimos para a segunda etapa de nossa pesquisa: construir o conceito de autonomia com os alunos e transferi-lo para a aprendizagem em sala de aula. Para tal, propusemos uma discussão que envolvesse uma definição de autonomia e exemplos práticos dessa habilidade. O objetivo dessa discussão era buscar no conhecimento prévio dos alunos um ponto de partida para o nosso objetivo principal: fomentar a autonomia em sala de aula. Embora a maior parte dos alunos não tenha conseguido elaborar uma definição para autonomia, eles puderam relatar histórias pessoais em que agiram com certo grau de autonomia. Como podemos observar nos depoimentos ${ }^{5}$ contidos no quadro 1.

\footnotetext{
${ }^{4}$ Peer correction

${ }^{5}$ Os nomes dos alunos são fictícios, preservando assim a anonimidade dos mesmos.
} 


\begin{tabular}{|c|c|}
\hline TURMA A & TURMA B \\
\hline $\begin{array}{l}\text { "Eu antes tinha que estudar com a minha } \\
\text { mãe para a escola hoje estudo sozinho. Ela } \\
\text { só me faz as perguntas no final.” (Paulo, } \\
10 \text { anos) } \\
\text { "Quando eu aprendi a jogar tênis. } \\
\text { Primeiro eu tinha aula, agora eu sei } \\
\text { jogar.” (Joaquim, } 9 \text { anos) } \\
\text { "No vídeo game a gente primeiro tem que } \\
\text { ler as instruções do jogo, depois a gente já } \\
\text { joga sozinho" (David, } 9 \text { anos) }\end{array}$ & $\begin{array}{l}\text { "Quando não tenho ninguém para me } \\
\text { servir vou até a geladeira e preparo o meu } \\
\text { lanche” (Joaquim, } 9 \text { anos) } \\
\text { "Quando minha irmã está chorando e } \\
\text { minha mãe está dormindo, eu dou um } \\
\text { brinquedo para minha irmã parar de } \\
\text { chorar e eu continuar a ver TV” (Estela, } 9 \\
\text { anos) } \\
\text { "Quando estou na natação me troco e vou } \\
\text { sozinha para a aula de tênis." (Leo, } 10 \\
\text { anos) }\end{array}$ \\
\hline
\end{tabular}

Quadro 1: Depoimentos dos alunos sobre autonomia

As histórias relatadas pelos alunos indicaram que eles já agem autonomamente em vários contextos, como por exemplo, nas tarefas domésticas, no esporte, no vídeogame e também no estudo. Embora alguns alunos ainda associem autonomia simplesmente à capacidade de serem independentes (Turma B), outros alunos já têm uma visão de autonomia como uma capacidade individual alcançada através de algum tipo de aprendizado. A partir desses exemplos, conversamos com a turma sobre a importância da autonomia em sala e, apoiados no vídeo que havia sido gravado na aula anterior, discutimos como poderíamos melhorar a nossa aula tendo o conceito de autonomia como objetivo.

O passo seguinte foi a elaboração de um pôster com estratégias que poderiam auxiliar a turma no desenvolvimento da autonomia em sala. Cada turma elaborou um pôster diferente (Anexo 2). O critério para a escolha das estratégias que seriam incluídas no pôster foi discutido e votado nas turmas. É importante destacar que as estratégias contidas em cada pôster buscavam fomentar algumas características de autonomia que precisavam ser maximizadas ou implementadas em cada turma. No quadro 2 pode-se observar a correspondência entre as características de autonomia que nos propusemos a seguir e as estratégias contidas nos pôsteres. 


\begin{tabular}{|l|l|}
\hline \multicolumn{1}{|c|}{ CARACTERÍSTICAS } & \multicolumn{1}{c|}{ ESTRATÉGIAS } \\
\hline $\begin{array}{l}\text { Autonomia requer consciência do } \\
\text { processo de aprendizagem; }\end{array}$ & $\begin{array}{l}\text {. Falar e participar. Ser responsável; (Turma A) } \\
\text { - Ler as instruções; (Turma B) }\end{array}$ \\
\hline $\begin{array}{l}\text { Autonomia, inevitavelmente, } \\
\text { envolve uma mudança nas } \\
\text { relações de poder; }\end{array}$ & $\begin{array}{l}\text {. Perguntar a três amigos antes de buscar auxílio } \\
\text { com a professora; (Turmas A e B) } \\
\text { - Ajudar os amigos; (Turma A) } \\
\text { - Respeitar os amigos; (Turma A) }\end{array}$ \\
\hline $\begin{array}{l}\text { O professor pode ajudar o } \\
\text { aprendiz a ser autônomo tanto na } \\
\text { sala de aula quanto fora dela; }\end{array}$ & $\begin{array}{l}\text { B) Usar o dicionário e outros recursos; (Turmas A e } \\
\text { - Seguir sozinhos o plano de aula disponibilizado } \\
\text { no quadro; (Turma B) }\end{array}$ \\
\hline $\begin{array}{l}\text { Autonomia está intimamente } \\
\text { relacionada às estratégias } \\
\text { metacognitivas; planejar/tomar } \\
\text { decisões, monitorar, e avaliar. }\end{array}$ & $\begin{array}{l}\text { - Avaliar participação e aprendizagem. (Turma A) } \\
\text { - Escolher uma atividade para ser conduzida sem a } \\
\text { interferência da professora; (Turma A) } \\
\text { da aula; (Turma B) } \\
\text { - Decidir a forma como querem trabalhar; (Turma } \\
\text { B) }\end{array}$ \\
\hline
\end{tabular}

Quadro 2: Correlação entre aspectos da autonomia e as estratégias utilizadas.

Ao longo de dois meses os pôsteres ficaram expostos no mural da sala e eram acessados regularmente pelos alunos. Observamos que algumas estratégias foram mais facilmente e rapidamente incorporadas do que outras. A fim de verificar que estratégias foram essas, decidimos fazer com os alunos uma avaliação final do nosso projeto. Esta avaliação buscava não só descobrir as estratégias mais comuns, mas também avaliar se havíamos conseguido promover algum tipo de mudança de postura em nossas turmas em relação à autonomia. Elaboramos então um questionário (Anexo 3).

Na primeira pergunta do questionário, observamos que alguns alunos foram capazes de elaborar definições de autonomia baseadas na sua própria vivência em sala e na experiência que tiveram ao longo dos dois meses do projeto. Ao contrário das respostas que coletamos no início do nosso trabalho, os alunos demonstraram ter agora um entendimento mais consciente e prático do que é autonomia, como podemos observar nas definições ilustradas abaixo:

“Autonomia em sala de aula é trabalhar em grupo.”

“Autonomia em sala de aula é trabalhar com um amigo.”

“Autonomia é procurar no livro o que você não sabe.”

“Autonomia é antes de perguntar algo para a professora, perguntar aos seus amigos.” 
“Autonomia é depender menos da professora, e mais de você.”

Na segunda pergunta do nosso questionário, observamos que a maioria dos alunos experimentou todas as estratégias sugeridas, e poucos foram os alunos que relataram nunca ter utilizado uma estratégia contida no pôster (quadros 3 e 4). O uso da maior parte das estratégias durante as aulas, mesmo que sem muita regularidade, revela um aumento no grau de autonomia nas duas turmas. Isso porque, ao utilizar uma estratégia o aluno já está trabalhando pelo menos uma característica da autonomia e, portanto desenvolvendo essa habilidade. Observamos também que algumas estratégias foram mais utilizadas do que outras. Na turma A, por exemplo, as estratégias mais utilizadas foram: ajudar e respeitar os amigos. Na turma B as estratégias foram: usar o dicionário e decidir a ordem das atividades. Essas estratégias estão relacionadas com as seguintes características da autonomia que pretendíamos desenvolver: mudança nas relações de poder, ajudar o aprendiz a ser autônomo, tomar decisões, monitorar, e avaliar.

\begin{tabular}{|c|c|c|c|c|}
\hline ESTRATÉGIAS & SEMPRE & $\begin{array}{c}\text { QUASE } \\
\text { SEMPRE }\end{array}$ & ÀS VEZES & NUNCA \\
\hline Usar o dicionário. & 1 aluno & 2 alunos & 4 alunos & 1 aluno \\
\hline Usar o livro. & 2 alunos & 0 aluno & 4 alunos & 2 alunos \\
\hline $\begin{array}{l}\text { Perguntar a três amigos antes } \\
\text { de buscar auxílio com a } \\
\text { professora. }\end{array}$ & 1 aluno & 4 alunos & 2 alunos & 1 aluno \\
\hline Ajudar os amigos & 3 alunos & 3 alunos & 2 alunos & 0 aluno \\
\hline $\begin{array}{l}\text { Falar e participar. Ser } \\
\text { responsável. }\end{array}$ & 2 aluno & 1 aluno & 5 alunos & 0 aluno \\
\hline $\begin{array}{l}\text { Escolher uma atividade para } \\
\text { ser conduzida sem a } \\
\text { interferência da professora. }\end{array}$ & 2 alunos & 3 alunos & 3 alunos & 0 aluno \\
\hline $\begin{array}{l}\text { Avaliar participação e } \\
\text { aprendizagem. }\end{array}$ & 2 alunos & 4 alunos & 2 alunos & 0 aluno \\
\hline Respeitar os amigos. & 1 aluno & 6 alunos & 1 aluno & 0 aluno \\
\hline
\end{tabular}

Quadro 3: Resultados da resposta 2 do questionário. (Turma A). 


\begin{tabular}{|l|c|c|c|c|}
\hline \multicolumn{1}{|c|}{ ESTRATÉGIAS } & SEMPRE & $\begin{array}{c}\text { QUASE } \\
\text { SEMPRE }\end{array}$ & ÀS VEZES & NUNCA \\
\hline $\begin{array}{l}\text { Perguntar a três amigos } \\
\text { antes de buscar auxílio com a } \\
\text { professora. }\end{array}$ & 0 aluno & 5 alunos & 5 alunos & 0 aluno \\
\hline Usar o dicionário. & 5 alunos & 2 alunos & 2 alunos & 1 aluno \\
\hline $\begin{array}{l}\text { Usar o livro e o caderno de } \\
\text { anotações. }\end{array}$ & 4 alunos & 1 aluno & 3 alunos & 2 alunos \\
\hline $\begin{array}{l}\text { Decidir a ordem das } \\
\text { atividades contidas no plano } \\
\text { de aula. }\end{array}$ & 5 alunos & 2 alunos & 2 alunos & 1 aluno \\
\hline $\begin{array}{l}\text { Decidir a forma como } \\
\text { querem trabalhar. }\end{array}$ & 5 alunos & 0 aluno & 3 alunos & 2 alunos \\
\hline $\begin{array}{l}\text { Seguir sozinhos o plano de } \\
\text { aula disponibilizado no } \\
\text { quadro. }\end{array}$ & 2 alunos & 0 aluno & 7 alunos & 1 aluno \\
\hline \begin{tabular}{l} 
Ler as instruções. \\
\hline
\end{tabular} & 2 alunos & 2 alunos & 5 alunos & 1 aluno \\
\hline
\end{tabular}

Quadro 4: Resultados da resposta 2 do questionário. (Turma B)

Alguns alunos acrescentaram alguns comentários sobre como o uso das estratégias refletiu na autonomia em sala de aula. Esses comentários mostraram que os alunos concluíram o semestre mais conscientes do processo de aprendizagem. Alguns desses comentários são:

“Usar o livro. Agora eu olho sempre no livro.” (Joaquim, 9 anos)

“Procuro as palavras no dicionário.” (Estela, 9 anos)

“Agora falamos mais inglês.” (Mauro, 9 anos)

“Eu acho que aprendi mais rápido porque fui independente seguindo os steps.” (Ângela, 10 anos)

"Eu aprendi mais porque cada vez que olho no dicionário, aprendo outras palavras além daquela que fui procurar.” (Lucia, 9 anos)

“A turma ficou muito mais organizada depois que fizemos o pôster.” (João, 10 anos)

Na última pergunta do questionário, em que pedimos uma auto-avaliação e uma avaliação da turma, os alunos demonstraram uma atitude positiva em relação ao desenvolvimento da autonomia em sala. A maioria dos alunos das turmas A e B avaliou a autonomia da turma com notas acima de 7 , sendo que dos dezoito alunos participantes 
da pesquisa, dez avaliaram a turma com notas entre 9 e 10. Ou seja, a maior parte dos alunos percebeu uma diferença no comportamento da turma no final do semestre. Já na auto-avaliação, embora a maioria das notas também tenha sido acima de 7, a maior parte das notas dadas pelos alunos, se concentrou entre 8,9 e 7. Esse resultado da autoavaliação pode ser interpretado como uma consciência crítica maior que nossos alunos desenvolveram em relação ao seu papel na turma e no processo de aprendizagem.

\begin{tabular}{|c|c|c|}
\hline & Nota da Turma & Minha Nota \\
\hline De 10 a 9 & $\begin{array}{l}\text { Turma A - } 5 \text { alunos } \\
\text { Turma B - } 5 \text { alunos }\end{array}$ & $\begin{array}{l}\text { Turma A }-1 \text { aluno } \\
\text { Turma B }-4 \text { alunos }\end{array}$ \\
\hline De 8.9 a 7 & $\begin{array}{l}\text { Turma A - } 2 \text { alunos } \\
\text { Turma B }-5 \text { alunos }\end{array}$ & $\begin{array}{l}\text { Turma A }-5 \text { alunos } \\
\text { Turma B }-5 \text { alunos }\end{array}$ \\
\hline De 6,9 a 5 & $\begin{array}{l}\text { Turma } \mathrm{A}-1 \text { aluno } \\
\text { Turma B - } 0 \text { aluno }\end{array}$ & $\begin{array}{l}\text { Turma A }-2 \text { alunos } \\
\text { Turma B }-1 \text { aluno }\end{array}$ \\
\hline
\end{tabular}

Quadro 5: Resultados da pergunta 3 do questionário.

\section{CONSIDERAÇÕES FINAIS}

Nossa pesquisa teve um duplo objetivo: refletir sobre o papel da autonomia na aprendizagem de inglês e promover a autonomia dentro da sala de aula através da construção de estratégias.

Como já mencionamos, há um consenso entre alguns autores (Leffa, 2002; Freire, 1977; Moita Lopes, 1997) de que a autonomia não é algo dado, mas alcançado através de treinamento e conscientização. Em nosso trabalho, tomamos essa premissa como base para promover a autonomia em sala de aula. Nos dois meses em que conduzimos a pesquisa, observamos que as estratégias propostas e aplicadas durante as aulas contribuíram para o entendimento e desenvolvimento da autonomia em nossos alunos. Contudo, é importante reforçar que só instrumentalizar os alunos pode não ser suficiente para o sucesso desse processo. O papel do professor como mediador desse processo também é vital, pois sua atuação em sala de aula tem grande influência sobre os alunos fazendo-os compreender o que se passa em sala de aula, influenciando-os de certa forma em suas escolhas e criando oportunidades de autonomia. Além disso, acreditamos que o fato do aprendiz ter a oportunidade de construir e elaborar suas 
próprias estratégias impulsiona o aprendizado autônomo, possibilitando ao aprendiz a transferência de conhecimentos adquiridos em sala para outros contextos.

Além desses fatores instrumentais, observamos também que o contexto parece exercer um papel importante no desenvolvimento da autonomia. Nas duas turmas pesquisadas constatamos que quando a interação é privilegiada, o ambiente torna-se altamente favorável para o desenvolvimento da autonomia. Em nossas aulas, muitas atividades estão centradas na interação, com o mínimo de intervenção do professor. Essas atividades criam um ambiente colaborativo, em que os alunos ajudam uns aos outros e são levados a pensar em termos de uma independência positiva e coletiva. Isso significa dizer que os alunos não agem competitivamente e individualmente, mas sim cooperativamente e em termos do grupo.

As constatações abstraídas da nossa pesquisa indicam que, com o uso regular de estratégias e assistência guiada do professor, podemos ensinar nossos alunos a serem mais autônomos. Acreditamos que ao gerarmos oportunidades de aprendizagem autônoma estamos contribuindo para a formação de aprendizes mais conscientes e eficientes. Muitas vezes, como professores, nos vemos inclinados a um comportamento centralizador em sala de aula, porém devemos lembrar que isso pouco contribui para uma aprendizagem sustentável. Acreditamos que o bom aprendizado é aquele que ensina o aluno a caminhar sozinho.

\section{REFERÊNCIAS}

Freire, P. (1996). Pedagogia da autonomia: saberes necessários a Prática Educativa. São Paulo: Paz e Terra.

Freitas, A.C. de. (1998) A aprendizagem consciente=aprendizagem eficiente? Letras \& Letras, 14.1: 59-72.

Larsen-Freeman, D. (2000). Techniques and Principles in Language Teaching. Oxford: Oxford University Press.

Leffa, V.J. (2002). Quando menos é mais: a autonomia na aprendizagem de línguas. Trabalho apresentado no II Forum Internacional de Ensino de Línguas Estrangeiras (II FILE). Pelotas: UCPel, agosto de 2002. Disponível em www.leffa.pro.br, acesso em 2007.

Moita Lopes, L. P. (2005). Interação em sala de aula de língua estrangeira: a construção do conhecimento. In: Moita Lopes, L.P. Oficina de Linguística Aplicada. 5.ed. Campinas: Mercado da Letras. 
Nicolaides, C. S. (2005). Inglês no contexto de Hong Kong: um olhar de fora em relação ao aprendizado autônomo de línguas. In: Freire, M.M; Vieira Abrahão, M.H e Barcelos, A.M.F. (orgs). Lingüística Aplicada e Contemporaneidade. São Paulo, SP: ALAB; Campinas, SP: Pontes Editores.

Nunan, D. (2000). Autonomy in language learning. Plenary presentation, ASOCOPI Cartagena, Colombia. October, 2000. Disponível em www.nunan.info/presentations/autonomy, acesso em 2008.

Oliveira e Paiva, V. (2005). Autonomia e Complexidade: uma análise de narrativas de aprendizagem. In: Freire, M.M; Vieira Abrahão, M.H e Barcelos, A.M.F. org. Lingüística Aplicada e Contemporaneidade. São Paulo, SP: ALAB; Campinas, SP: Pontes Editores.

Oliveira e Paiva, V. (2006). Autonomia e Complexidade. In: Linguagem e Ensino. Revista do Curso de Mestrado em Letras. Universidade Católica de Pelotas. Volume 9. Número 1. ECUCAT.

Vigotski, L.S. (1998) A Formação Social da Mente. São Paulo: Martins Fonte. $6^{\mathrm{a}}$ ed.

\section{AS AUTORAS}

Célia Angélica Limani Boisson Moraes graduou-se em Psicologia pela PUC - Rio em 1983. Concluiu o curso de Educação Infantil e Necessidades Especiais pelo Centro Educacional de Niterói em 2009. Viveu 4 anos na Inglaterra onde obteve o certificado de Proficiência em língua inglesa pela Universidade de Cambridge. É professora de língua inglesa há 19 anos em cursos livres, tendo sido coordenadora de um deles durante 10 anos. Leciona também em escolas particulares e, em uma das escolas, atua como Coordenadora de inglês no segmento de Educação Infantil e Ensino Fundamental desde 2004. Elaborou um curso de inglês para fins específicos na área de gastronomia, atuando nesta área desde 2007. Email: celia_boisson@yahoo.com.br

Paula Silveira Gardel concluiu o mestrado em Estudos da Linguagem pela PUC-Rio em 2006. Graduou-se em Letras Português - Inglês pela UFRJ, Universidade Federal do Rio de Janeiro em 1991. Cursou a Pós-Graduação Lato Sensu (Especialização) em Língua Inglesa pela PUC-Rio em 1999. Leciona há 20 anos em cursos de idiomas privados, tendo sido também Coordenadora de um deles por um período de 10 anos. Atualmente leciona na UERJ como professora substituta no Departamento de Linguística, e na PUC-Rio como professora de inglês do CCE, no IPEL línguas. Atua na área de ensino de língua estrangeira e Linguística Aplicada, com ênfase no ensino de inglês.

Email:paulagardel@gmail.com 


\section{ANEXO 1}

\section{LANGUAGE ANALYSIS}

1) Do you Japanese? No, I am American.

2) Why do you happy?

3) You are a sumo wrestler?

4) You are happy?

5) I from Brazil?

6) I have yen years old.

7) On Saturdays, he gets up and eat breakfast.

8) Paul don’t like computer games.

9) I'm can run and draw.

10) I have a brother. Her name is Paul. 
ANEXO 2

Poster 1: Turma A

1. Look up words in the dictionary.

2. Check information in your book.

3. Ask three friends before asking your teacher.

4. Help your friends.

5. Speak and participate. Be responsible.

6. Choose 1 activity every class to work without your teacher's help.

7. Evaluate your participation and learning every class.

8. Respect your friends. 


\section{Poster 2: Turma B}

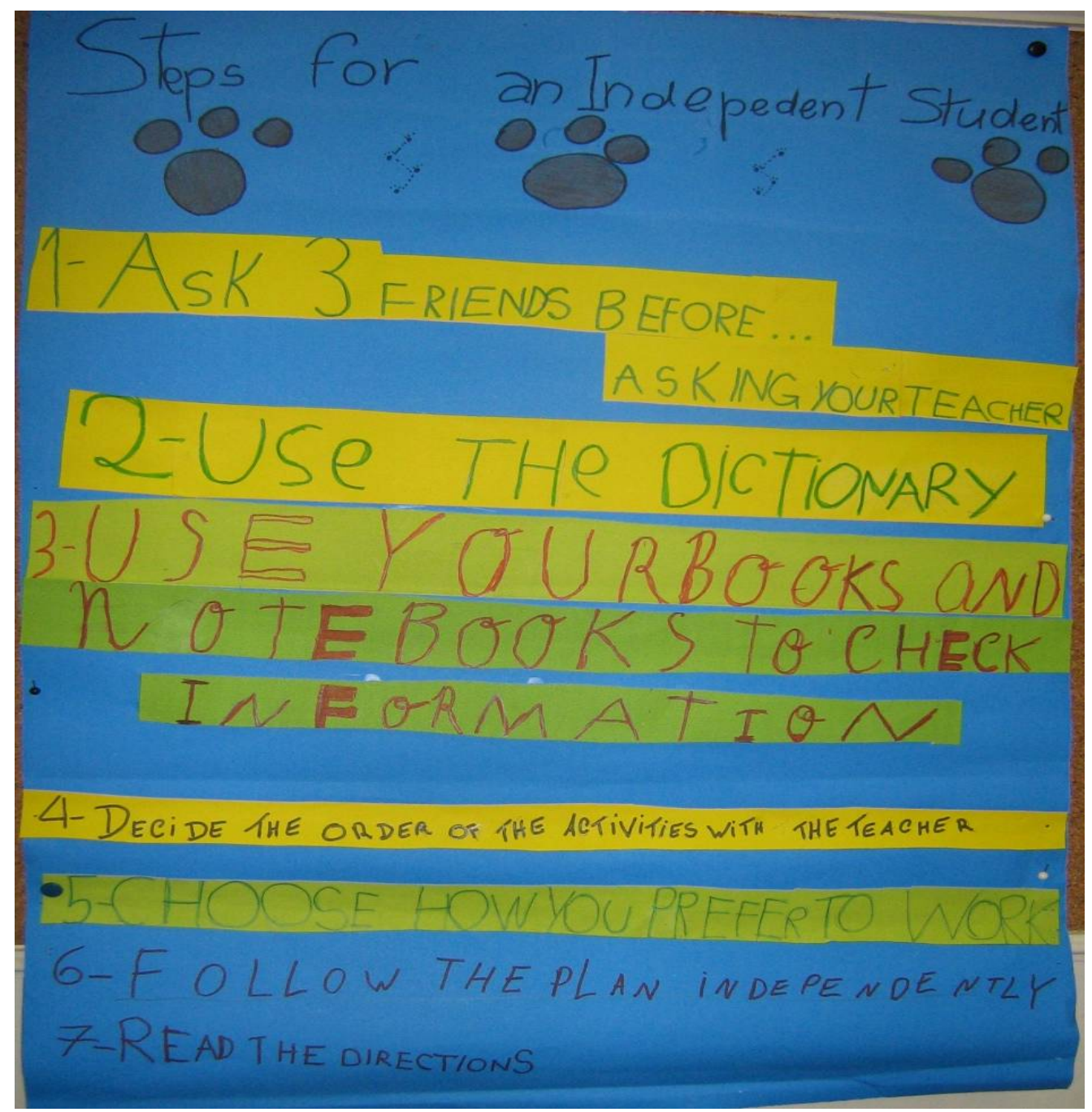


ANEXO 3

\section{QUESTIONÁRIO}

1. Autonomia em sala de aula é

Exemplo:

2. Marque com um X os "steps” mais usados por você e pela turma:

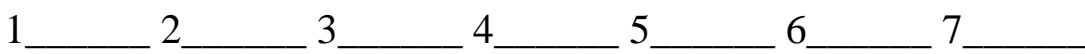

Você acha que esses “steps” ajudaram a aumentar a autonomia? Dê um exemplo.

3. Dê uma nota de autonomia para você e para a turma $(1-10)$

Nota da turma Sua nota 